\title{
i-Soc: An Info-Sociological Approach to Structural-Agent Causal Symmetry
}

\author{
Shing-Chung Jonathan Yam
}

Department of Sociology, The Chinese University of Hong Kong, Hong Kong, China; chung@link.cuhk.edu.hk

Received: 2 March 2020; Accepted: 15 April 2020; Published: 20 April 2020

check for updates

\begin{abstract}
In this article, I discuss the sociality of information flow by investigating a momentous yet often-neglected side of it-the reinforcing info-causal loops between habitus and structures. I treat habitus as a principled agent and explain how structure sustains itself (under the framework of Fiske and Pinker et al.) by upholding principles as goals or reducing them into subroutines (goal subjugation). At the structural level, four dominant categorical schemes-game theory, network analysis, systems functionalism, and field theory-are investigated for the characteristic information flow that they can capture. The result is an info-sociological approach that acknowledges causal symmetry between structure and agents.
\end{abstract}

Keywords: ontology vs. epistemology; sociology of knowledge; sociology of communication; information sociology; field theory

Nonetheless, he belonged to Work. [...]

Nobody dared to deny Work's wish. That's disrespectful to the social system.

Because Kakfa belonged to it.

—Master Jonjon, The Last Kafka of Work (2013)

This paper presents an info-sociological approach that treats structure and habitus as causally symmetrical to each other. This symmetry problem has baffled social/communication scientists because of the complex and ad hoc ways in which society, a multi-levelled construct, has its patterns spread across analytical levels that interact with each other [1-3]. In the last sixty years, each major tenant of the sociology of communication has highlighted their choice of infrastructure supporting these interactions: sign systems over media [4-6], medium characteristics [7], symbolic capital [8-10], and, more recently, the power to decide who connects to whom [11]. Infrastructures tend to persist and are readily observable-a common prerequisite to sociologistic conceptions of society. But, in this paper, I argue that information, at least at the structural level, has a similar persistent property irrespective of the choice of categorical schemes. Through studying the regularity of the ways agents pass on information, I propose a novel approach to understand causal relationships between political, economic, and cultural structures and habitus by studying the perpetual effects of information flow. I contend that structure filters and enforces specific kinds of info-mechanism, giving rise to a regularity that tends to cancel out the multidirectional effects of (local) informational interactions and instead aggregate them into a collective information process (incidentally, making the latter describable and analyzable).

Extending $[8,12]$ 's field theory to informational interactions, I shall show that this results in a regularity that reinforces a directed information flow between structures and habitus (and the latter's characteristic input-output pairs), thus forming a meta-theory supporting many of the basic structural-habitus interactions already enlightened by theorists from both sides. My first step would be to capture and analyze these interactions at the meso-level, between structure and the computational 
efforts of habitus. ${ }^{1}$ The distinction ceases to be relevant, because this paper will focus on societal structure and individual agents only. By this terminology, I draw special focus to the causal procedures of the socio-psychological side of habitus, giving rise to an understanding of habitus' basic operations that have been captured multiple times by precursors of information sociology (e.g., Bourdieu's internationalization of structure or Hussrel's intentionality as per the phenomenological route). Similarly, I shall also explore the structural side by dissecting the four dominant categorical schemes for structure-game theory, network analysis, systems functionalism, and field theory-thereby illuminating how academics have conceptualized information flow among a group of agents with differentiated structural positions. This would once again lead us to a meta-theoretical understanding, this time for the forms of regularity we can/cannot capture through the four lenses. Through this, we would have moved one step towards understanding symmetry as a causal loop by reorienting habitus as structure-facing (developed through 'structured structure' as per Bourdieu) and structure as habitus-facing.

This exercise serves as a starting point for three purposes: (i) a brief outline of habitus computation, as situated within structures, where our sociology's prevalent field-capital-habitus theory, as propelled by Bourdieu, has fallen short of; ${ }^{2}$ (ii) the characteristic information flow (societal)/informational interactions (interpersonal) of society, which would lead to (iii) a novel info-sociological resolution to the structural-agency problem. This paper shall mainly focus on (i) and (ii), with a hint on (iii), which I shall elaborate in future publications by focusing on each kind of structure separately. Throughout my argument, I would explore with a powerful example of information-ideology—to illustrate how habitus generates information within unequal structures and how structure constrains information production and processing for its own reproduction. Attention will be directed to characteristic informational interactions [14] between and within levels as a starting point to understand the internal logic of society—between structure, habitus, and information—an approach that I shall refer to as i-Soc theory, given its central attention in information and a 'hyphenated' coalescence with the latter's binding structures of agents.

This paper has three sections. The first section, socio-psychological i-Soc, centres on habitus as an interpersonal interface for informational interactions. I shall start with how the word 'habitus' is used among its proponents and relate each form of sociality (here, I use [15,16]'s exhaustive categories for these forms) to principles that habitus can adopt. By further contending that there are three such principles, this completes the cognitive side of our structural-agent causal loop. These principles are derived from the way humanity is perpetually preserved by its distinctive computational capability, namely, a universal form of intelligence. Attention is directed to the structural differentiation of habitus, as structural position determines privileges. The second section, structural i-Soc, instead starts at the opposite end and explores societal structure with the four categorical schemes that have been extensively studied in social science and how competent they are in capturing specific types of information flow. The final discussion section concludes by delineating the boundaries of i-Soc, thereby reifying a reflexive position for information sociology.

\section{On its Socio-Psychology}

We shall start with how 'habitus' is normatively conceptualized within any given structure. Much has been said about 'habitus' in the phenomenological literature and its sociological successors, most notably by $[8,9,17,18]$. Connotations of the term thus expand through the years and, in all of them, habitus resides in individuals and mediates between sociality and behaviour. First, habitus can be dispositions, or simply 'habits' [19]. Here, habitus is a descriptive term used for the prediction

1 This statement makes no distinction between the problems of structural-agency and micro-macro divide. Differences between the two arise from applying (artificial) categorical schemes to slice up society, which can be clarified by specifying the perspective doing the slicing - one of my aims in Structural i-Soc theory.

2 A psychological account of this deficiency can be found in [13]. 
of behaviour acquired or inborn. Second, habitus can be deterministic or semi-deterministic, as in field-capital-habitus theory [8]. Depending on one's reading of Bourdieu's text, the voluntaristic habitus can diminish and fall under structural constraints acquired through socialization. Third, habitus can be seen as historical constructs-products of experience giving rise to categorized social constructions, which can be descriptively defined as 'structures of consciousness' [20] or a procedural 'life-world' [21]. Finally, habitus can be seen as a 'structuring structure' [9] (p. 53), where objective societal realities are captured in collective subjectivity, which then leads to strategic social action.

This would mean that field logics are to be recorded by and hence and reside within subjectivity. But then, how does this translate into social action, or, more specifically, what types of computational process await these inputs? This is an issue of motivation, which has to go beyond [10]'s specification of the 'feel' as to how various fields affect, because the specification fails to cater for what habitus wants before engaging with those fields. Or, as [22] (p. 379, emphasis in original) put it, habitus is a 'generative structure of practical action', thereby acquiring agent behaviour once field causations are put aside for the moment. This constitutes a wild empty space for a psychologistic side to our sociologistic discussion so far [23].

\subsection{Principled Agent}

To fill in this void, I further propose habitus as a principled agent. Principles are pure, specific goals. But they also 'control . . . how something happens or works' ${ }^{3}$, and that something in this case is the only loophole of the habitus conception of individuality-the (voluntaristic) agency apparently capable of breaking free from structure. To see how a limited number of principles can be applied to the infinite environmental possibilities confronting agents, we can start our discussion with abstractions of sociality, and study how each of them invokes specific principles. This gives us a simpler picture, for $[15,16]$ have compiled an exhaustive list of social forms with only three flavours: dominance, reciprocity, and communality.

In this sense, we can narrow down our focus to the computational tendencies as embedded in each of these in-memory social forms. We can start at the individual level—habitus' computational efforts ex ante the decisions of others. But this results in both causal and deductive loops, leading to infinite regresses. Some forms of [24]-style bounded rationality can help, but they still share the complexity problem of heterogeneous thinking styles. Fortunately, the discussion can be simplified in another way, by considering what $[15,16]$ have captured-social forms that exist and persist to the point worthy of description. We may then model intrapersonal changes as social shocks that move one form to another.

But the problem of finding a general computational direction for our causal loop is yet to be solved. What does the habitus want? Among endless possibilities, there are preferences that are abstracted from spacetime because decision making continues in ever new (e.g., social) situations. We can approach this potentiality of habitus from two opposite directions. The first would be to appeal to basic individual/collective human nature-an approach adopted by classical knowledge sociologists, who were phenomenologically informed. This would include, for example, [25,26]'s 'co-feeling' and the 'loving participation' in a world of wonders and meanings. The opposite direction deals with normative questions in a more explicit way-the renowned critical school, in which [27] gave us a list of criteria and procedures of how communication should proceed. And now, history suggests that these ideals are difficult if not impossible to realize despite modernity's notable structural changes, after which we are drifting no closer with these theorists themselves struggling with the social structures of their time. We can, however, place our sociological imagination once again in the failure of these utopias and learn from how they are structurally suppressive, and investigate how habitus is to cope with such suppression.

3 Cambridge Dictionaries Online. (2015). Principle. Retrieved 11 March 2015 (http://dictionary.cambridge.org/dictionary/british/ principle). 
We can start with the problem-solving nature of habitus, a natural intelligence that fights against a hostile environment so competently as the speciality of humanity, for, finally, in the history of organisms, it pertains to an analytical capability to approach, with ever more accuracy, (objective) truth-seeking and objective choice evaluation. These capabilities thus open up novel causal pathways within social structures, e.g., by enacting cultural assumptions to any primitive forms of sociobiology. Here, objective evaluation is none other than moral evaluation, having taken the widest universal scope-an intelligence involving here is thus the contemplation of others' contemplation (and ad infinitum) as a simulation exercise. And this contemplation requires a level of appreciation of others, which is then to be situated within a structure of domination (to disregard others in full), or, at the other end of the spectrum, that of communality (unsurprisingly to be found in families with its powerful 'internalization' effect, e.g., [28]), which presupposes overall welfare within the scope of resources that such communal arrangements permit. Reciprocity lies, controversially, between these two ends of the spectrum-its progression depends on a socioeconomic context defining one's position [29] that can steer relationships away in either direction.

This lays out one-half of the framework of our required causal symmetry by describing how the positioning of habitus in structures is causally looped with the relative 'strengths' of its principles. But do not be misled by the word 'disregard', for while in any case a planning habitus can contemplate others' position, knowing does not imply caring. A pure case of this disregard is strategic action-the pursuit of welfare for oneself as an analytical construct [30]. The implication of strategic action is biological and existential-habitus, just as other systems, has to confront its most urgent problem, that of its continued existence in the physical world. But a biological being can also move past existence, because additional welfare contributes to wellbeing. The strategic side of habitus is thus complementary to altruism, the two kinds of evaluation combined to make up the coin of morality. With these two conflicting scenarios, we can thus construct habitus, bottom-up, as based on a set of conflicting principles to be capitalized/suppressed/dropped by its informational interactions with its environment in the form of sequences of input-output pairs.

\subsection{Three Habitus Principles}

This gives us the following three principles for habitus: one general computational goal of survival/wellbeing and two requiring objective reasoning.

\subsubsection{Principle of Self}

The primary aim of the Principle of Self is to preserve habitus against the uncertainty of death-existence takes precedence over actions from other principles—but can as well go beyond and into its welfare. While existence builds upon biological simplicity, complexity surges in welfare improvement-value-driven, hence open to indefinite operationalization [14], even in the narrow sense of a strategic (or confusingly, 'rational') choice. And if wider choice-value systems are brought in, there is this further tautological problem-over-defining self-interest-by posing 'rationality' as broad as what leads to any positive emotive states, hence conceptually unhelpful if we are to apprehend positive-emotive non-self motivations, i.e., altruism. Ignoring the latter would under-capture humanity's biological capabilities as social beings, a false start heading to inaccurate analyses of causal symmetries. To approach is to first delineate, and hence here we highlight the contrast between altruistic consequences-while acknowledging that they can perfectly be positive emotive states but through different values and/or behaviour-and 'self-regarding payoffs' [31] (p. 95, emphasis in original). That way, the varied ways of decision making will resurface from our over-generalized theoretical landscape and can be analyzed against this principle. The principle only considers self-regarding payoffs as its goal.

With the principle in place, its underlying values thus direct the meaning-making process behind improvement-definitions - over time, to prepare for the future self. Meaning making is locked in the spacetime trajectory of existence but with a hopeless twist, in the end, with no future. Meanings beyond this trajectory are therefore incomprehensible. 


\subsubsection{Principle of Knowledge}

But then the meanings beyond are indeed comprehensible- though speculative-and this we have to move on to objective principles—at times to be appreciated by habitus—and in the case of the Principle of Knowledge-directed to the improvement of collective epistemic states with elements of truths albeit partial. Knowledge sociologists are used to subjugating truth-seeking endeavours under the self (as in [31]'s psychological presumptions), which is then to be limited by a society's technological capacities (rationalism and methodological empiricism). Knowledge generation in this sense is not pure, given its sociologistic emphasis on a capital-network system.

Alternatively, Collins' introductory assumptions are purer-of curiosity or 'emotional energy' [32] (p. 20) (reflective of $[25,26]$ 's 'loving participation' in 'wonders'), forming a genuine interest. Abstracted from an existential need, this phenomenological lineage thus speaks against our modern, utilitarian use of our environment and economic sociality (being 'pragmatic', which Scheler critiqued). By following this distinction, we can distill out an intrinsic form of knowledge generation that is then subject to structural logic. In this pure form of knowledge generation, curiosity meets two simple ends-the energetic spirit ready to organize the confusing and the confusing so abundant keeping it engaged.

Now contrast this with the case in which the principle gets subjugated under self. Here, instead, the pragmatic provides a functional prerequisite (gravely articulated by [33]) given the self's primacy. This subjugation has mixed effects on goals. The self has no interest in honesty (the bare retelling of one's knowledge set) or collective knowledge generation. Further dishonesty kicks in to reduce cognitive dissonance when the two principles conflict-both with each other ([34]'s original focus) or with the possibility of carrying out planned actions [35]. Before these actions can be aggregated, non-truth-seeking behaviour has to first be commonly maintained and reinforced-as with other collective mechanisms—which maintains and reinforces ('stable') societies together and their information sets.

And at least as part of the causal loops this has to facilitate confirmation depending on the degree of collective goal subjugations. At the psychological level, it starts with the tendency to not falsify hypotheses [36]. At the structural level, this transforms into convergence (implicated by [36]) but also polarization (multiple mechanisms, e.g., discordant repulsion [37]) in other times. Here, we must not forget initial conditions-examples include the existence of substructures (e.g., political parties) or a monolithic totality (traditional societies). But what is convergence, in the case of in-group favouritism, as it is just the same as polarizing against out-group(s)? This forms a general direction for structural sustenance, determining the kinds of information stored in collective subjectivity and how.

But before we move on to structure, let us have a look at the last principle of habitus.

\subsubsection{Principle of Morals}

We are now down to our final piece for our causal symmetry at the agent side. Here, morality, as in our last principle, also takes an objective stance, but now directed to an overall welfare improvement combining altruism with self. Its objectivity thus comes with impartial evaluation, and, as is the case with knowledge, it stems from humanity's level of universal intelligence-including the ability to simulate others' thought processes, engendering appreciation (as a kind of simulation)—understanding and co-feeling [38]. The main enemy to this impartiality is the expansion, or over-evaluation, of self; in this respect, morality has to work against the innate tendency of self over altruism and hence empirically requires the strengthening of the latter.

This objectivity within knowledge sociology pertains to a rational view of morality. We can rewind through all the novelties of pessimism and unanalyzable chaos to trace the field's constructive positions back through Scheler to Husserl to Rickert and to Kant [39,40]—as relevant to our current discussion, innate, unconditional, empirically possible only hence doomed to be violated in some contingencies-'categorical imperative'. From this checkpoint, it was as if knowledge seeking (logics and methodology) had become the causal basis of morals. But before we celebrate this bootstrap 
simplicity, we do have to consider carefully the question of goal selection-for getting a simulation and knowing its results (as so much explored by Habermas) is different from the appreciation of its results as an ultimate aim (as complained recently by [41], although many of the issues there were more of a want-of-knowledge scenario). It is through this distinction that we can see such knowledge as capabilities/tools (hence, a subroutine), while morals will continue to operate anyway, relying on the various levels of these tools' availability [42,43]. We should therefore focus on morals as an evaluative component also pertaining to universalism but this time in terms of appreciation (a central concept of $[39,40])$. And we seem to have these prerequisites after all—co-feeling exists—rather than—as how Hobbes [44] has preoccupied himself with—to subjugate such universalism under self.

What we have achieved so far is a glimpse into social cause-effects via the cognitive-to provide a basis for non/mobilization, information un/reproduction, or whatever that goes against structural logic. This is the agent-dominant side to our causal symmetry, where human capabilities-wherever possible and prevailing over the natural environment-do get manifested (a situation of 'structure-less' social gathering, pertaining to simple aggregation perspectives such as game theory ${ }^{4}$ ). But even if we are to put the three principles in their respective places, the question of how they subjugate within each other is another story - this takes place within sociological realities, as designed by agents each with a different set of initial conditions. We can readily see how the degree of freedom of this can grow beyond comprehension, a mess that is reality defying any elegant description. And while this is why social change is underrepresented in the study of structural logic [45], in the remaining of this article I shall at least deal with the case of a strong social structure as a starter. And it is at this point that structural logic has to and can be added back to the picture, replacing the transcendental language of free will and institutionalized beliefs-a set of controversies that haunted $[39,40]$ when he tried to save morality from natural science.

\subsection{Example: Political Structure with Two Ideologies}

Let us illustrate the relevance of our cause-effect pairs with a powerful social phenomenon: ideology and its political structure. The vast analytical communication literature on ideology has taken two routes: the unconscious/psychological (through Lacan and Althusser) and the critical school (sociopolitical-then economic-function, through classical and the early knowledge sociologists). While they both treat ideology as irrational and detached from reality, they both tend to-before Giddens and Bourdieu-refer inwards, with 'narcissism' in the former and structural mandates in the latter. But principled agents also need an interface, a filter before each theorist's favourite habitus operation can respond to structural mandates on value choice. Through these interfaces, ideology legitimizes the nature and direction of information flow and mobilizes resources (as both incentives and threats) to affect the habitus' adoption of principles.

This is where causal loops linger as a self-sustaining information flow. Example: preoccupations to stigmatize counterfactual reasoning against the structure at hand. As political structure is an unequal structure, let us differentiate between structural positions with the simplest level of two and call them oppressor and oppressee ideologies. Both ideologies induce the viewing of personal attributes as the reason for personal consequences (ignorance of structural relationships), structural conservatism (success/failure stories that 'explain' hence maintain structural positions), and the suppression of both knowledge and morals. But there are also differences. The oppressor ideology entails a strategic lifestyle (vanity), but some truth-seeking behaviour is left—only as a subroutine under self, an idiosyncrasy that is then passed down from generations alongside an exclusive access to knowledge (inequality in education). But not all kinds of knowledge are necessary, because as long as the maintenance function is concerned, the ideology will then facilitate its own design and implementation. This constraint

4 Aggregating all the way to society-level—hence violating the 'structure-less' presumption-leads to an assumption mismatch as demonstrated by descriptive, analytical and predictive problems in orthodox economics. 
keeps the mind simple so that habitus output is kept within a small set, predictable and manageable. The inequality in knowledge means that power is vested in its exclusive possession as an instrument [46].

Contrarily, the oppressee ideology is more acute in that it induces the routinization of ideological information processing (brainwashing). This leaves only the individualistic self intact with curiosity stigmatized. The self is then subject to the oppressor-designed structure to elicit more predictable responses. Barred from a capability to pursue truths and moral evaluations, the strategic self can only further oppress other oppressees, which maintains cognitive consonance with structural logic. This creates a sequence of oppressor-oppressee dyads but rewards to oppressees tend to diminish over time as power inequality reproduces, leaving them with ever-poorer choices. A direct implementation here would be the criminalization of truth-seeking behaviour. Lacking such behaviour, structural reproduction prevents its self-refutation. Instead, ideology reproduces into a political doxa as counterfactuals are removed by the oppressee self, having been left alone, as an unimaginative being that seeks to maximize whatever it is.

We can thus see how desire and narcissism - as per the unconscious route-result in actions upon structure vis-à-vis specific forms of representation of reality. This causation comes in the form of a memory as a structuring structure, which simplifies reality both theoretically and methodologically. Simplification is a necessity as per limited computational faculties. A designed structure thus provides this prerequisite by cutting off access to taboo facts, perpetuating directed confusion, conspiracy-thinking or xenophobia.

Let us move one step backwards in causation to open the last box.

\section{On its Structure}

We are now ready to explore the opposite end of our causal symmetry-society. Unfortunately, understanding here is much constrained by our limited language/computational ability: the Central Dogma of Social Science [47] requires all-encompassing perspectives to come low on determinacy for the purpose of apprehension. We are thus left with partial solutions from multiple disciplines. Here, I shall explore how the four dominant structural perspectives in social science describe info-causal social phenomena: game theory, network analysis, systems functionalism, and field theory. I shall start with their basic framework, treating them as categorical schemes that highlight components of society. I will also use ideology to demonstrate how they portray this strongest kind of information flow within structure and the precise info-processes that they can capture.

\subsection{Game Theory}

Game theory predicts outcome with the simple aggregation of individual choices. Sociality is simplified to the point that optimal decisions are actually possible-the realist assumption on common knowledge of world/worldviews (modelling ever more complex incomplete information sets comes with soaring complexity and forfeits game theory's mathematical elegance). We can thus treat information flow in a game as steps of a computational device. It comes with the understanding of the world (input) and the deductive reasoning that follows (computation). ${ }^{5}$ Nonetheless, this is a huge simplification, to the point that computational social models can exist (e.g., [48]). Consequently, outcomes stem from deduction and hence carry no further information. This is an approach that makes very little distinction between causation and deduction-structure is simply a pre-set of rules that also fixes everybody's preferences.

We can explore reductionistic approaches by examining what is left out. Here, I discuss the two consequences of the way information flow is conceptualized from this simplification. First, it is evident that the usual games provide much less information to its participants than real-life social

5 Alternatively, more-recent advancements that relax some stringent assumptions would allow for experimentation in choices and understanding of others, for example, in sequences of interaction as in the empirical study of iterated games. 
situations. Consequently, the opposite is also often the case-insufficient information to make a definite choice [30] with deduction starting at arbitrary points with no unique strategy. A second resort, calculably probabilistic reasoning, is thus in place of complex knowledge-seeking behaviour, e.g., mutual observation and evaluation of trust. Such complex behaviour becomes impractical given that humans differ from each other, resulting in heterogeneous operationalization-in terms of what the 'self' wants, further complicated by how it is to be combined with altruistic motivations (e.g., altruistic utility) [30,49-51]. Moreover, personality and cultural assumptions as prior knowledge can lead to variances in goal subjugation as well as the level of trust for and in general what to expect from others [51]. These differences are often not common knowledge, exacerbating the problem of inability to make a choice. To reduce these 'irregularities', the orthodox interpretation of game theory thus has to make further assumptions, e.g., by exclusively considering the self, ignoring more nuanced psychological gains or the possibility of knowing others better through experimentations, and so on.

This interpretive rigidity also leads to a second neglect: power reproduction here is nested within game rules, but utility matrices in real life are instead set up socio-historically by past key players. These are to be inherited downwards, a temporal dimension to rule-setting in real-life power inequality. This works through complex sociolinguistic and institutional mechanisms, including threats, the silencing of commentary on power inequality, and ideological control [52]. The power of the oppressor is thus greater than a simple, statically defined game can capture. In this sense, ideology acts as choice inhibitors- the removal of choices available to others leaving them with ever-worse ones.

\subsection{Network Analysis}

The next reductionistic perspective we shall study is network analysis, which models structure as interpersonal relationships: the existence of ties (adjacency, the existence of an edge) between nodes (vertices). Both the nature and meaning of the nodes and ties are de-emphasized, what is left is thus the existence of interpersonal relationships as explanations of causal loops (perpetuation of link-makings and breakings). Ironically, the absence of many relationships is what makes network analysis useful, because it is their absence that makes existing relationships valuable and vested with power so that non-adjacent nodes have to rely on routes provided by others.

A drawback to network analysis is the possibility of powerful extra-network entities-a kind of boundary specification problem $[53,54]$. These 'confounding variables' require further theories and intuition to justify the studying of particular networks as they are, either as defined by research subjects ('realist' approach) or the analyst ('nominalist' approach) [55]. Ignorance on meaning-making practice is also unenlightening to structural inequality and sustenance-besides centrality in a graph structure, it is the threat-implied and coercive nature of information throughout a society that makes a node powerful.

For a long time, frameworks like [56] have represented the standard way to do network analysis: sociologistic (ties constraint nodes rather than the other way around) and a focus on emerging relationship patterns (bottom-up). This simultaneously rejects the aggregated, black-box-until-opened approach to society offered by systems functionalism, and the voluntarism of agents (e.g., that people are making those relationships). The opposite side of the spectrum is $[57,58]$, who reinstalled culture into the picture by looking at how language maintains networks. A central notion to this cultural-network perspective is the role of stories:

Pair balancings of control efforts can become generalized as a set of stories held in common. And indirect ties can gain standing in some strings of ties and stories ... And networks and ties are also shaped by storied shadows from identities that have vanished or did not come into being. [58] (p. 26)

With this unexpected addition, a network is then maintained through a persistent 'meaning structure', the latter of which takes the centre stage in information dissemination giving rise to the former as observable results [59]. Through this analytical distinction, meaning structure thus imposes 
on interpersonal transactions [59] —and readily intrudes into the other concepts, having incorporated a large repertoire of unobservables from collective subjectivity ${ }^{6}$.

By considering only graphs with limited ties, propagation happens in slow, iterative steps. This offers an opposite worldview to game theory (where all information is open to everyone before any analysis kicks in unless otherwise stated) and tends to be sensitive to local-spatial informational interactions. However, ideology typically comes with broadcasting abilities-an uninteresting network structure. On the contrary, the key strength here is to draw attention to local versions of ideologies, or the dissemination of secrets, relying on scarce middle-humans, a situation that crystallizes into incentives to interact, forming dyadic patterns of conflicts and cooperation. Truth-seeking behaviour is to be limited by the availability of ties and comes at odds with the action of retelling, or reinforcements within overlapping spheres of meaning making. Network analysis thus can illuminate how ideologies get individually passed down, modified, re-encoded throughout its journey, where local sites of power emerge and take advantage.

\subsection{Systems Functionalism}

The previous two perspectives present structure as a flat space unless further complications are introduced (e.g., directed graphs). Contrarily, systems functionalism presumes a compartmentalized, operational hierarchy. It can thus be equally viewed as a design process-inspired as an engineering paradigm, one that allows simplification with divide and conquer until it reaches its limit at the macro side constituting a natural, noisy environment.

The way systems functionalism falls out of fashion together with Parsons (as explored by many e.g., [60]) is a cautionary tale that has become irrelevant, disappearing from the talk of social scientists. But the lure of assuming that function comes with existence with the resultant linguistic convenience means that it is to stay, as a latent perspective more influential than many may realize. This convenience comes with a number of costs. The distinction between causation and functional design is muddled (especially when unintended consequences and conflicting structures are taken into account), leading to a focus only on social equilibria [61]. This limits our focus onto a narrow range of social realities, the ones in which information flows either across social subsystems as cooperative partners or downwards as survival needs and in turns to be rewarded with pre-implemented results. Naturally, ideology performs this function of stability maintenance but with one obvious catch - that within the realm of politics it presupposes how one party exerts power over another, hence entailing a designed, domination/conflict situation. This raises the inconvenient question of function for whom (an issue that Merton attempted to patch with limited success).

This pertains to a more fundamental question to structure as an anthropomorphic conception in which a designer creates a system that would then follow a life path of calculated stability. Bringing back the system designer reveals a vested interest that needs to be shielded from interactions with the rest of the system-for example, a walled 'palace'. But then at this point, the lack of discussion on how individuals constitute a cooperative whole becomes apparent (a deficiency more explicit in self-reproducing systems, e.g., [62]), for info-causal loops between individuals and the larger system brings in soaring complexity not without logical problems [63]. From forerunners $[64,65]$ to the 'neofunctionalists' [66], these loops aggregate individual differences into not only functional procedures but also the ever differentiation of structural positions_-an inconvenient truth that requires silencing empirically unless some core assumptions are to be lifted. It is in this sense that systems that are conceivable under this paradigm are those extremely pre-aligned, one with a strong information flow that loops with functional requirements from system to designers and ideology from designers to agents of implementation, generating a need for reflexive design/implementation.

6 However, while using the language of network, it is doubtful as to how communicable these extensions are to other network analysts. 


\subsection{Field Theory}

As a metaphor borrowed from physics, fields (as in our familiar field-capital-habitus theory $[10,15]$ ) diffuse over space with a decreasing concentration of influence. Here, what we can come of, is that strategic action is the result of getting to know each field's logic and relevant participants' in-field position. But, at this point, it is apparent that such logic transcends beyond the calculating self, and, consequently, Bourdieu's metaphoric use of 'economy', where a reconciliation is needed with the emotive drives/affections arising from the 'socialized body' to social structures [67]. It transcends because field is such a ubiquitous concept that overshadows the competitive practice (e.g., sports) that Bourdieu has focused on especially in his earlier theoretical journey. It is hard to reconcile because the link between strategy and emotion can be operationalized in many ways, which is-as our discussion on game theory has revealed-particularly impossible, when strategy requires/emotion depends on knowing each others' strategies/emotions ad infinitum.

But sociality does move on as if choices are possible with participants as well as fellow socio-structural theorists simplifying the seemingly impossible-by focusing only on this strong-field/stable society situation where information and its interpretations are normatively regulated. This can be readily observed in traditional societies, where privileged habitus, being informed of this collective subjectivity, can coerce collective executions through enforcing the 'orthodoxy' of movement within fields. This can also be seen in our information society, where restrictions on who can use what information perpetuate a gap in meaning-making practice, and in the case of routine/'pop' information, that of cultural reproduction [68].

In these scenarios, information flows (in the form of commands, containing explicit rules to be turned into norms) from both collective subjectivity and privileged habitus to memories of fields and, finally, to habitus of the undermined. Fields persist in records and collective subjectivity and hence continue to influence, after their producers are long gone, often in unintended ways. We can investigate how collective preservation works through studying conversations and the lack thereof (taboos, where conversations happen internally often unconsciously). In any case, the role of ideology lies on coercion, indicating asymmetric information flows, produced, maintained, and propagated with designed reactions.

Conversely, the opposite direction is weak. It entails residual, reactionary outputs, which are then fed back to the privileged and its bureaucracy for fine adjustments (a causal asymmetry of sociologism). Moreover, these reactionary outputs scatter across the masses and require a level of aggregation to reach social meanings/actions (borrowing Bourdieu's terminology—the praxis that comes out of individual emotive drives). Unequal field logic thus goes against moral/truth-seeking reasoning: the silencing of positioning and trajectory information and the evaluation thereof. Now the coercive nature of unequal fields is generic in the sense that they govern the relative ability to carry out any of the aforementioned analyses and evaluations. This is the structural-dominant side to our causal symmetry, where structure builds itself to the point (a situation by considering 'society' is by-default 'stable', a focus hence giving rise to structural social theories) that agent influence becomes trivial/choice set is restricted towards routine activities. This is none other than the tendency for any given structure to sustain itself.

\section{Discussion}

In the last section, we have reviewed the four ways in which informational interactions can take place within structure-a set of common rules flow through habitus computation, doxa-formation with powerful middle-humans providing incentives for exchange, predesigned channels of commands and feedbacks facilitate operation, and field logic designed by the privileged executes within collective subjectivity. In the spirit of principal component analysis, I have also done a brief investigation of power and its resultant information flow, ideology.

Now we can see how causal symmetry can be so easily missed; an ontological context here being cohesion. If the labelling of a group as a society is to have assumed it is having a considerable level of stability, structural-dominant causal asymmetry will result-for these structures 
are pre-designed to counter out/suppress agent creativity, either directly or more subtly through socializing (e.g., within economic field [69]). On the other hand, the agent-dominant side of our story is to flourish in advocatory or small-group settings within ad-hoc environments, or if we focus on privileged habitus only. This understanding of causal symmetry leads us to the contexts in which structure and agents counter out each other's effect with respect to the variety of info input-output pairs made possible.

Some key omissions are to be noted here. First, informational interactions presume meaning-making practice and are hence discursive, but there are other types of interaction as well. This calls for an 'i-Matter' theory, the residual theoretical environment of i-Soc. This would also open up discussions as to why and how some elements of the material world are selected and seen as pivotal and/or informative, and more importantly, those that are not. We can see hints of this from [70,71]'s frame analysis, but with a shift of focus from actors' available choices to contexts of sociality.

Second, there are at least three types of structure-political, economic, and cultural—with their own logics of information flow. The first two are unequal structures, while the last one is a structure of differentiation that can, among other things, accentuate the other two through providing an alternative causal pathway. In this article, I have painted the explicit side of power only while [52] has long reminded us of the lesson of subtlety.

Third, structure stabilizes with the help of the ongoing fine-tuning of collective subjectivity over time, so as an empirical exercise, a socio-historical analysis is most helpful to see how our familiar structures, stereotypically believed to be the only kinds, can get to shape into their current existence. This would become substantial when our discussion moves on to the nuances of intersectionality [14]. I shall deal with these three issues in upcoming publications when time permits.

Funding: This research received no external funding.

Conflicts of Interest: The author declares no conflict of interest.

\section{References}

1. Giddens, A. The Constitution of Society; University of California Press: Berkeley, CA, USA, 1984.

2. Turner, J.H. Theoretical Principles of Sociology Vol. 3: Mesodynamics; Springer: Berlin/Heidelberg, Germany, 2012.

3. Williams, A. Political Hegemony and Social Complexity: Mechanisms of Power after Gramsci; Palgrave Macmillan: London, UK, 2020.

4. Baudrillard, J. The System of Objects; Verso: Hong Kong, China, 2006.

5. Baudrillard, J. The Consumer Society: Myths and Structures; SAGE Publications: Thousand Oaks, CA, USA, 1998.

6. Baudrillard, J. Symbolic Exchange and Death; SAGE Publications: Thousand Oaks, CA, USA, 1993.

7. Mcluhan, M. Understanding Media: The Extension of Man; Routledge classics: London, UK, 2001.

8. Bourdieu, P. Distinction: A Social Critique of the Judgement of Taste; Routledge: London, UK, 1984.

9. Bourdieu, P. The Logic of Practice; Stanford University Press: Palo Alto, CA, USA, 1992.

10. Bourdieu, P.; Wacquant, L.J.D. An Invitation to Reflexive Sociology; University of Chicago Press: Chicago, IL, USA, 1992.

11. Castells, M. The Information Age: Economy, Society and Culture Vol. III: End of Millennium; Blackwell Publishers: Cambridge, MA, USA, 2000.

12. Bourdieu, P. The Rules of Art; Polity: Oxford, UK, 1996.

13. Burawoy, M.; von Koldt, K. Conversations with Bourdieu: The Johannesburg Moment; University of the Witwatersrand Press: Johannesburg, South Africa, 2012.

14. Yam, S.-C.J. Survival guide to grand theorizing and the Central Dogma of Social Science. Drustvena Istrazivanja (J. Gen. Soc. Iss.) 2016, 25, 199-218. [CrossRef]

15. Fiske, A.P. The four elementary forms of sociality: Framework for a unified theory of social relations. Psychol. Rev. 1992, 99, 689-723. [CrossRef] [PubMed]

16. Pinker, S.; Nowak, M.A.; Lee, J.J. The logic of indirect speech. Proc. Natl. Acad. Sci. USA 2007, 105, 833-838. [CrossRef] [PubMed] 
17. Wacquant, L. Body and Soul: Ethnographic Notebooks of an Apprentice-Boxer; Oxford University Press: New York, NY, USA, 2004.

18. Wacquant, L. Habitus as topic and tool: Reflections on becoming a prizefighter. Qual. Res. Psychol. 2011, 8, 81-92. [CrossRef]

19. Camic, C. The matter of habit. Am. J. Sociol. 1986, 91, 1039-1087. [CrossRef]

20. Husserl, E. Experience and Judgment; Northwestern University Press: Evanston, IL, USA, 1973.

21. Schutz, A. The Phenomenology of the Social World; Northwestern University Press: Evanston, IL, USA, 1967.

22. Lizardo, O. The cognitive origins of Bourdieu's habitus. J. Theory Soc. Behav. 2004, 34, 375-401. [CrossRef]

23. Emmerich, N. Ethos, eidos, habitus a social theoretical contribution to morality and ethics. In Dual-Process Theories in Moral Psychology; Cordula, B., Ed.; Springer: Berlin/Heidelberg, Germany, 2016; pp. 271-295.

24. Simon, H.A. Theories of bounded rationality. In Decision and Organization; Mcguire, C.B., Radner, R., Eds.; North-Holland Publishing Company: Amsterdam, The Netherlands, 1972; pp. 161-176.

25. Scheler, M. On the Eternal in Man; SCM Press: London, UK, 1960.

26. Scheler, M. On the positivistic philosophy of the history of knowledge and its laws of three stages. In The Sociology of Knowledge: A Reader; Curtis, J.E., Petras, J.W., Eds.; Duckworth Books: London, UK, 1970.

27. Habermas, J. The Theory of Communicative Action, Volume 1: Reason and the Rationalization of Society; Beacon Press: Boston, MA, USA, 1985.

28. Berger, P.L.; Luckmann, T. The Social Construction of Reality: A Treatise in the Sociology of Knowledge; Penguin: London, UK, 1967.

29. Fiddick, L.; Cummins, D.D. Reciprocity in ranked relationships: Does social structure influence social reasoning? J. Bioecon. 2001, 3, 149-170. [CrossRef]

30. Gintis, H. The Bounds of Reason: Game Theory and the Unification of the Behavioral Sciences; Princeton University Press: Princeton, NJ, USA, 2009.

31. Gintis, H. Rational Choice Explained and Defended. In The Mystery of Rationality; Di Iorio, D., Bronner, G., Eds.; Springer: Berlin/Heidelberg, Germany, 2017.

32. Collins, R. The Sociology of Philosophies: A Global Theory of Intellectual Change; Belknap Press of Harvard University Press: Cambridge, MA, USA, 1998.

33. Arendt, H. The Human Condition, 2nd ed.; The University of Chicago Press: Chicago, IL, USA, 1998.

34. Festinger, L. A Theory of Cognitive Dissonance; Stanford University Press: Palo Alto, CA, USA, 1957.

35. Harmon-Jones, E.; Harmon-Jones, C.; Levy, N. An action-based model of cognitive-dissonance process. Curr. Dir. Psychol. Sci. 2015, 24, 184-189. [CrossRef]

36. Wason, P.C. On the failure to eliminate hypotheses in a conceptual task. Q. J. Exp. Psychol. 1960, 12, 129-140. [CrossRef]

37. Del Vicario, M.; Scala, A.; Caldarelli, G.; Stanley, H.E.; Quattrociocchi, W. Modeling confirmation bias and polarization. Sci. Rep. 2017, 7, 40391. [CrossRef]

38. Cornejo, C. Intersubjectivity as co-phenomenology: From the holism of meaning to the being-in-the-world -with-others. Integr. Psychol. Behav. Sci. 2008, 42, 71-178. [CrossRef] [PubMed]

39. Kant, I. Critique of Pure Reason; Cambridge University Press: Cambridge, UK, 1999.

40. Kant, I. Groundwork of the Metaphysics of Morals, Revised ed.; Cambridge University Press: Cambridge, UK, 2012.

41. Bloom, P. Against Empathy: The Case for Rational Compassion; Ecco Press: Manhattan, NY, USA, 2016.

42. Damasio, A.; Damasio, H. Exploring the concept of homeostasis and considering its implications for economics. J. Econ. Behav. Organ. 2016, 126, 125-129. [CrossRef]

43. Johnson, M. Morality for Humans: Ethical Understanding from the Perspective of Cognitive Science; University of Chicago Press: Chicago, IL, USA, 2014.

44. Hobbes, T. Leviathan; CreateSpace Independent Publishing Platform: Scotts Valley, CA, USA, 2011.

45. Swartz, D. Symbolic Power, Politics, and Intellectuals: The Political Sociology of Pierre Bourdieu; University of Chicago Press: Chicago, IL, USA, 2013.

46. Foucault, M. Discipline and Punish; Pantheon: New York, NY, USA, 1977.

47. Yam, S.-C.J. Invitation to Information Sociology. Available online: http://www.globalmediajournal.com/ open-access/invitation-to-information-sociology.php?aid=62528 (accessed on 18 April 2020).

48. Gintis, H.; Helbing, D. Homo socialis: An analytical core for sociological theory. Rev. Behav. Econ. 2015, 2, 1-59. [CrossRef]

49. Branas-Garza, P.; Espinosa, M.P.; Rey-Biel, P. Travelers' types. J. Econ. Behav. Organ. 2011, 78, 25-36. [CrossRef] 
50. Colman, A.M. Game Theory and its Applications in the Social and Biological Sciences; Psychology Press: London, UK, 1995.

51. Gintis, H. Social norms as choreography. Politics Philos. Econ. 2010, 9, 251-264. [CrossRef]

52. Lukes, S. Power: A Radical View, 2nd ed.; Palgrave Macmillan: London, UK, 2004.

53. Kossinets, G. Effects of missing data in social networks. Soc. Netw. 2013, 28, 247-268. [CrossRef]

54. Valente, T.W.; Fujimoto, K.; Unger, J.B.; Soto, D.W.; Meeker, D. Variations in network boundary and type: A study of adolescent peer influences. Soc. Netw. 2013, 35, 309-316. [CrossRef]

55. Laumann, E.O.; Marsden, P.V.; Prensky, D. The boundary specification problem in network analysis. In Applied Network Analysis; Burt, R.S., Minor, M.J., Eds.; Sage Publications: London, UK, 1983; pp. $18-34$.

56. Berkowitz, S.D. An Introduction to Structural Analysis: The Network Approach to Social Research; Butterworths: London, UK, 1982.

57. White, H. Identity and Control: A Structural Theory of Social Action; Princeton University Press: Princeton, NJ, USA, 1992.

58. White, H. Identity and Control: How Social Formations Emerge, 2nd ed.; Princeton University Press: Princeton, NJ, USA, 2008.

59. Fuhse, J.A. The meaning structure of social networks. Sociol. Theory 2009, 27, 51-73. [CrossRef]

60. Hempel, C.G. The logic of functional analysis. In Readings in the Philosophy of Social Science; Martin, M., Mcintyre, L.C., Eds.; Massachusetts Institute of Technology: Cambridge, MA, USA, 1994; pp. 349-375.

61. Isajiw, W.W. Causation and Functionalism in Sociology; Routledge and Kegan Paul: London, UK, 1968.

62. Luhmann, N. Social Systems; Stanford University Press: Palo Alto, CA, USA, 1995.

63. Turner, J.H.; Maryanski, A.R. Is 'neofunctionalism' really functional? Sociol. Theory 1988, 6, 110-121. [CrossRef]

64. Durkheim, E. The Division of Labor in Society; Free Press: New York, NY, USA, 1997.

65. Durkheim, E. The Elementary Forms of the Religious Life; Free Press: New York, NY, USA, 1965.

66. Alexander, J.C. Neofunctionalism and After: Collected Readings; Wiley-Blackwell: Hoboken, NJ, USA, 1998.

67. Aarseth, H. Eros in the field? Bourdieu's double account of socialized desire. Sociol. Rev. 2016, 64, 93-109. [CrossRef]

68. Bourdieu, P.; Passeron, J.C. Reproduction in Education, Society and Culture, 2nd ed.; Sage Publications: London, UK, 1990.

69. Hayes, A.S. The behavioral economics of Pierre Bourdieu. Sociol. Theory 2020, 38, 16-35. [CrossRef]

70. Goffman, E. Frame Analysis: An Essay on the Organization of Experience; New edition; Northeastern University Press: Boston, MA, USA, 1986.

71. Goffman, E. Forms of Talk; University of Pennsylvania Press: Philadelphia, PA, USA, 1981. 